\title{
A New Era-We Welcome Our Collaboration with Springer!
}

\author{
Joseph F. O'Donnell
}

Published online: 10 March 2010

(C) Springer 2010

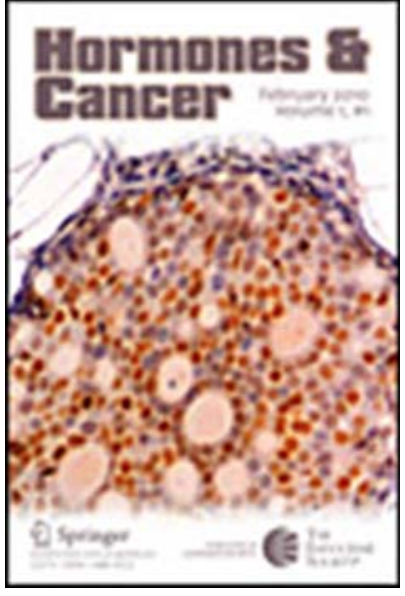

In the last editorial, I wrote for issue 24-4, I wrote of our decision to switch to Springer as our new publisher. It is sad to leave Taylor and Francis and especially Sean Beppler, our wonderful liaison editor there, but we felt that the opportunities at Springer were exactly what we needed to grow, and now, we joyfully embrace that partnership.

We are especially excited about the assets that Springer offers: We now have an online submission and review system, the benefit of having papers published online very quickly after acceptance with Springer's OnlineFirst ${ }^{\circledR}$ program, a page budget of 500 pages per year in four issues (and a plan to attack our backlog), wonderful marketing opportunities all over the world, and a fabulous senior publishing editor, Rachel R. Warren, who will work with a Springer team who is dedicated to help us improve. Yes, we'll get our impact factor up!

J. F. O’Donnell ( $\square)$

Editor-in-Chief, Journal of Cancer Education,

Hanover, NH, USA

e-mail: joseph.odonnell@dartmouth.edu
This is indeed a new era, and we need all of you to help improve the quality of the journal by submitting your best work and spreading what you learn from the journal to others so that we can really live our motto of "decreasing the burden of suffering from cancer in the world through effective education." I hope you will like our new cover and format, and please visit the journal's new Springer home page to learn more: http://www.springer.com/biomed/ cancer/journal/13187.

The journal changes do not come in isolation. Frank Ferris and the AACE executive committee have updated the society's website, http://www.AACEOnline.com. It will now act as a portal and be a "go to" site for resources to improve cancer education. As an example, visit the materials Frank put together on using Powerpoint ${ }^{\circledR}$ effectively.

One of the goals for this volume, Volume 25, is to pay tribute to founding editor Dick Bakemeier and his wife Alice, who served as his editorial assistant for years. As I try to do this job and keep my sanity, I marvel at all Dick and Alice did to build the strong foundation. The editorial board has decided to invite a Richard Bakemeier Invited Paper each year, to focus on an important topic in cancer education. This year, we have asked Lenora Johnson and her team from the National Cancer Institute to review the data they presented at the annual meeting about effective published materials in cancer education, including what we have done in the JCE. We will also honor the top-cited articles from each year with a Dick Bakemeier prize. Finally, in a future issue, Dick Gallagher and I will each collate tributes to Dick.

On one sad note, I wanted to make the readers aware of the untimely death of former cancer training branch chief Vincent Cairoli, who was a great friend to cancer education. We wish his family our sincerest condolences. The field 
also lost another great friend, this time to a well-deserved retirement, when Lester Gorelic retired from the NCI. Vince, Lester, Bob Adams...Margaret Hay Edwards.....the world is a better place because of you! Thank you!!

I wanted to give specifics about Springer and all the opportunities which I include below:

\section{About Springer}

Springer is one of the largest scientific, technical, and medical journal publishers in the world, with a modern and innovative approach to selling and distributing scholarly journals. Springer maintains offices in over 15 countries worldwide, producing over 1,700 journals and more than 5,500 new book titles every year.

Through arrangements with over 300 academic library consortia worldwide as well as progressive market development in the Far East, Eastern Europe, and other developing countries, Springer plays a leading role in distributing research on a global scale. Springer also participates in numerous tertiary level philanthropic projects: In cooperation with governments, non-governmental organizations, donor organizations, and other aid organizations, Springer offers university and research institution libraries in selected developing countries an economically viable pricing model for access to their online publications.

\section{Cancer/Education Portfolio}

Springer has a dynamic portfolio of books and journals in cancer research, oncology, public health, and outreach, and the Journal of Cancer Education will become an important part of the Springer journal list. Related titles in several areas include Cancer Microenvironment; Cancer and Metastasis Reviews; Breast Cancer Research and Treatment; Cancer Immunology, Immunotherapy; Cancer Causes and Control; Supportive Care in Cancer; Journal of Cancer Survivorship; Journal of Public Health; International Journal of Public Health; Evolution: Education and Outreach; Advances in Health Sciences Education; Research in Science Education; International Journal of Science and Mathematics Education, and many others.

\section{The JCE and SpringerLink}

SpringerLink.com is Springer's online content delivery system, where full-text journal and book content is hosted and fully searchable on a single platform. It reaches more than 30,000 libraries around the world.
There are more than 1,700 journals and 19,000 books currently available on SpringerLink. The number of new book titles is projected to increase by more than 2,500 each year as new titles are published and digitized. SpringerLink reaches over 10 million desktops, resulting in approximately 2 million full-text article/chapter downloads per month.

\section{OnlineFirst ${ }^{\mathrm{TM}}$}

Springer's OnlineFirst ${ }^{\mathrm{TM}}$ service allows users to access peerreviewed articles well ahead of the print publication, with the potential for citable articles to be published within 8 days of entering the production workflow. These articles are searchable and citable by their DOI (digital object identifier), and hence, OnlineFirst ${ }^{\mathrm{TM}}$ significantly reduces the time it takes for critical discoveries to reach the research community.

\section{Open Choice ${ }^{\mathrm{TM}}$}

Springer Open Choice allows authors to have their journal articles made freely available to the public at no charge, in exchange for payment of a basic fee (an article processing charge).

All articles are peer-reviewed, professionally produced, and available both in print and e-version on SpringerLink. In addition, every article will be registered in CrossRef and included in the appropriate Abstracting and Indexing services. Springer OpenChoice articles have the possibility of incorporating additional non-text files such as sound or video in the electronic edition.

\section{Editorial ManagerTM}

Springer journal article authors submit manuscripts through an online submission program called Editorial Manager ${ }^{\mathrm{TM}}$. Editorial Manager ${ }^{\mathrm{TM}}$ is a web-based manuscript submission and peer-review system for scholarly journals, reference works, and conference proceedings. Using the system, authors submit original and revised manuscripts, editorial staff send manuscripts out for peer review, reviewers conduct reviews and return comments, and editors make final decisions.

I am very excited about this partnership and the future of the Journal of Cancer Education. Now let's all get to work to realize this potential and to live our aim: to reduce the burden of cancer in the world through effective education.

Sincerely,

Joseph F. O'Donnell, Editor-in-Chief

Dartmouth College 